9

\title{
Algebraic Schemes in Legal Thought and in Everyday Morality
}

\author{
Wilfried Hommers and Norman H. ANDERSON
}

Legal thought may have unique value for cognitive science. A primary characteristic of legal thought is its focus on valuation and integration of evidence. Even simple cases typically involve multiple pieces of evidence, each of which has to be evaluated for its implications with respect to the judgment to be made, and all of which have to be integrated to arrive at an overall judgment. In this respect, legal thought is similar to psychological decision theory, which is also concerned with valuation and integration of information.

What is distinctive about legal thought is that it has been in the process of development for centuries, as illustrated in the historical survey of the concept of recompense (Hommers, $1983 \mathrm{a}, 1986$ ). The legal thought of today embodies the thinking of generations of legal scholars. Legal thought thus represents a highly developed, albeit complex system of knowledge that has an active role in the operation of society. Lawyers and judges must become experts in the understanding and use of this system of knowledge. Their own cognitive processes are thus highly structured and so are of direct interest to psychological science.

It is the theme of this chapter that legal thought and cognitive theory have much to offer each other. They have natural commonality in their mutual concern with valuation and integration of evidence, as already noted, as well as commonality in relation to morality, which is as important in everyday life as in the law. Because of its long sociocultural development, legal thought may be considered an expert cognitive system, interesting in its own right, and also as a heuristic for the understanding of everyday morality. It should be fruitful, as Hommers $(1981,1985)$ has argued, to develop genuine two-way interaction between legal thought and cognitive theory.

Algebraic schemes of evidence integration are considered in this chapter to illustrate one area for developing mutual interaction between legal thought and cognitive theory. Algebraic schemes have been suggested by many writers on legal thought, perhaps as a natural consequence of the primary problem of quantifying judgment to fit the offense and the offender. Independently, algebraic schemes have been considered in many areas of cognitive decision 
theory, including moral judgment. These algebraic schemes provide an interesting area for the two-way interaction with mutual benefit to both fields. One moral issue is considered here to illustrate some possibilities for such twoway interaction.

\section{The Case of Recompense}

The case of recompense provides a good example for the study of algebraic schemes. Legal thought has long been concerned with recompense, as illustrated in the prescription of the Judaic code that four sheep shall be repaid for one stolen sheep (Exodus, 22, 1). Other examples are given in the historical survey by Hommers $(1983 \mathrm{a}, 1986)$. Recently, psychologists have also begun to study recompense in everyday morality (Piaget, 1932; Berscheid \& Walster, 1967).

The case of recompense emphasizes the problem of integration, for recompense does not stand alone but in relation to some harmful act. Hence it is necessary to integrate the damage from the act together with the recompense to arrive at a judgment of deserved punishment. But this is not enough, for legal thought and everyday morality both agree that the culpa, including intent and responsibility (Hommers, 1983 b), behind the harmful act must also be taken into account. Thus, all three variables have to be integrated to arrive at a judgment of deserved punishment.

One specific hypothesis, suggested by both legal thought and everyday morality, is that the integration obeys the simple algebraic scheme

\section{Deserved Punishment $=$ Culpa + Damage - Recompense.}

This may be called scheme $\mathrm{S}$, since recompense reduces deserved punishment by subtraction. This algebraic scheme parallels the blame schema studied in everyday morality (Anderson, 1983; Hommers \& Anderson, 1985; Leon, 1980; Surber, 1982) and also seems in line with $\S 46$ of the Penal Code from 1975 of the Federal Republic of Germany. According to Maurach, Gössel, and Zipf (1978), two components of sentencing are distinguished: harmdoer and act, which correspond to culpa and damage in the cited scheme. Recompense is considered to affect both components: it diminishes the damage caused by the act; and it raises the moral character of the harmdoer, thereby diminishing culpa which depends on both purpose and negligence. A related legal scheme appears in the concept of mitigating circumstances of the British Court of Appeal Criminal Division (Thomas, 1970).

However, a different legal scheme for recompense has also been proposed. This appears in the sentencing theory of the German legal scholar Von Linstow (1974), who proposed a formula with 15 variables for calculating punishment 
of traffic violations. Recompense was incorporated as a multiplicative factor with values between 0.8 and 1.0 :

Deserved Punishment $=($ Culpa + Damage $) \times$ Recompenes.

By this formula, values of recompense less than 1 would reduce the deserved punishment. This may be called scheme $M$, since recompense reduces deserved punishment by multiplication.

The existence of two different algebraic schemes raises two questions. First, which scheme ought the judge follow? This is the prescriptive question. Second, which (if either) scheme is actually followed in intuitive judgment, by laypersons or by experts? This is the descriptive or cognitive question. Both questions are interesting and important. As a prescription Von Linstow's calculation rule has been criticized by legal scholars (e.g., Bruns, 1974, 1980; Zipf, 1977). The present discussion, however, is primarily concerned with the cognitive question, which, nevertheless, is relevant to the actual operation of legal systems. Despite their focus on the prescriptive question, legal schemes must make some allowance for nonprescriptive facts: human processing capabilities and human values. Accordingly, it is desirable to find some empirical test of schemes $S$ and $M$.

A fundamental difficulty arises in any attempt to test such algebraic schemes. This concerns measurement of values and is relevant even in a prescriptive context. To use either of the two schemes as prescriptions for judges' decision making, as Thomas (1970) and Von Linstow (1974) suggest, would require prior measurement of the values of culpa, damage, and recompense. But values are to some degree intuitive, not prescriptive, and are left in greater or lesser degree to the discretion of individual judges. This is clearly necessary for culpa, which is not objectively measurable but rather an attribution made by the judge. Even damage may involve nonmaterial components, loss of reputation, for example, that must be evaluated by the individual judge's intuition. Although the same algebraic scheme may be prescribed for all judges, some nonprescriptive element of value must still be allowed for. Thus, even to apply schemes $\mathrm{S}$ and $\mathbf{M}$ as prescriptive rules is not generally possible without a means of measuring values.

This measurement problem appears even more strongly in the descriptive cognitive approach, for different individuals clearly have different values irrespective of which of the two schemes is employed. Cognitive theory cannot prescribe what values a person ought to have, but instead must take cognizance of what they are. Two persons may both use scheme $S$ to judge deserved punishment, but they will arrive at different judgments because they have different values, especially for the nonmaterial variable of culpa. To test whether they do indeed use scheme $S$, therefore, it seems necessary to know their personal values of culpa, damage, and recompense, for the values of one person will not add up to yield the judgments of the other person.

A solution to this problem of measuring individuals' values at the same time as testing the scheme's validity has been developed as part of the func- 
tional measurement methodology of the theory of information integration (Anderson, 1981, 1982). The essential idea of functional measurement is to use the algebraic structure of the scheme as the base and frame for measurement. If the algebraic scheme holds empirically, the data from a suitably designed experiment will exhibit a corresponding pattern. The pattern of the data is diagnostic of the operative scheme. The values themselves, moreover, may be derived from this data pattern. Functional measurement can thus transform the schemes from qualitative verbalisms to exact quantitative laws of cognition in combination with a solution of the measurement of the values.

The following experiment illustrates how functional measurement methodology may be applied to test schemes $S$ and $M$ in an exact way. The subjects in this experiment were laypersons. That was appropriate due to the demonstrational purposes of the experimental analysis, i.e., the testing of laypersons was not designed for drawing conclusions about actual expert decision-making. Since the very same method may be used to study judgments of legal experts, the extension of this approach to legal thinking is discussed in the second half of this chapter.

\section{Experimental Analysis}

Legal thought, as already indicated, has suggested two algebraic schemes for the effect of recompense. One claims that recompense is subtractive; the other claims that recompense is multiplicative. The experiment reported in this section illustrates how functional measurement methodology can be used to distinguish between these two schemes - while still allowing for personal values of each individual judge.

Previous work in this research program has found that recompense is nonadditive in its effects (e.g., Hommers \& Anderson, 1985). The pattern of the data thus disagreed with the subtractive scheme and was, indeed, consistent with a multiplying scheme. These results were not definitive with respect to the two schemes, however, because the same data pattern could be produced by an averaging rule with differential weighting for recompense. The averaging rule, however, has a cognitive structure similar to that of the subtracting scheme. The purpose of this experiment was to test between multiplying and averaging processes of recompense integration.

Using the stamp scenario of Hommers and Anderson (1985), subjects were told stories about two stamp collectors, one of whom ruined some stamps belonging to the other. They were told to imagine that they were the victim and to say how much the offender should be punished. The stories presented culpa, damage, and recompense information. The three levels of culpa described accidental, careless, and intentional acts. The two levels of damage stated that two or ten stamps were ruined. The three levels of recompense stated that none, half, or all of the ruined stamps were replaced by the offender. Subjects received information about just two of the three specified variables on each trial. 
This information was presented according to the two-factor designs shown in the three panels of Figure 9.1. In addition, judgments were obtained based on each single piece of information to provide scale-free, crossover tests that discriminate between the averaging and multiplying rules.

Subjects made their punishment judgments on a graphic rating scale. General procedure was similar to that used in previous experiments (Hommers \& Anderson, 1985) employing the methodology of functional measurement. Subjects were students from introductory psychology courses at the University of California, San Diego.

Three main results were obtained. First, the culpa-damage integration was additive, whereas the recompense-damage and recompense-culpa integrations were nonadditive. Second, the scale-free tests supported the averaging rule and disagreed with the simple subtracting and multiplying rules. Third, the paradoxically large effect of recompense observed in previous work was confirmed.

\section{Integration Rules}

The data are summarized in Figure 9.1, in which each panel represents the integration rule for one pair of information variables. In the left panel, the two solid curves portray the damage-culpa integration. The number by each curve represents the number of damaged stamps, so the difference between the two solid curves shows how the damage variable affects the judgement of punishment. The upward trend of these curves represents the effect of culpa, with more punishment being assigned for greater culpa.

The main characteristics of these two solid curves is that they are parallel. By virtue of the parallelism theorem (Anderson, 1981), this implies that damage and culpa are integrated by an adding-type rule. This replicates previous work that has studied these two variables (Hommers \& Anderson, 1985; Leon, 1980; Surber, 1982).

The three solid curves in the center panel portray the integration rule for recompense and culpa. These curves, however, appear to be quite nonparallel. Nonparallelism implies that the integration does not obey an adding rule. Similarly, the two solid curves in the right panel portray the integration rule for recompense and damage. Here again, the nonparallelism points to a nonadditive integration. Recompense is thus nonadditively processed.

\section{Evidence for Averaging}

Closer analysis of the data shows that the integration rule is actually one of averaging for all three pairs of variables. The averaging rule has some fundamental consequences for cognitive theory so the data analysis needs detailed consideration. The key to the analysis lies in the relation between the dashed curve and the solid curves in each panel. Each dashed curve represents judg- 


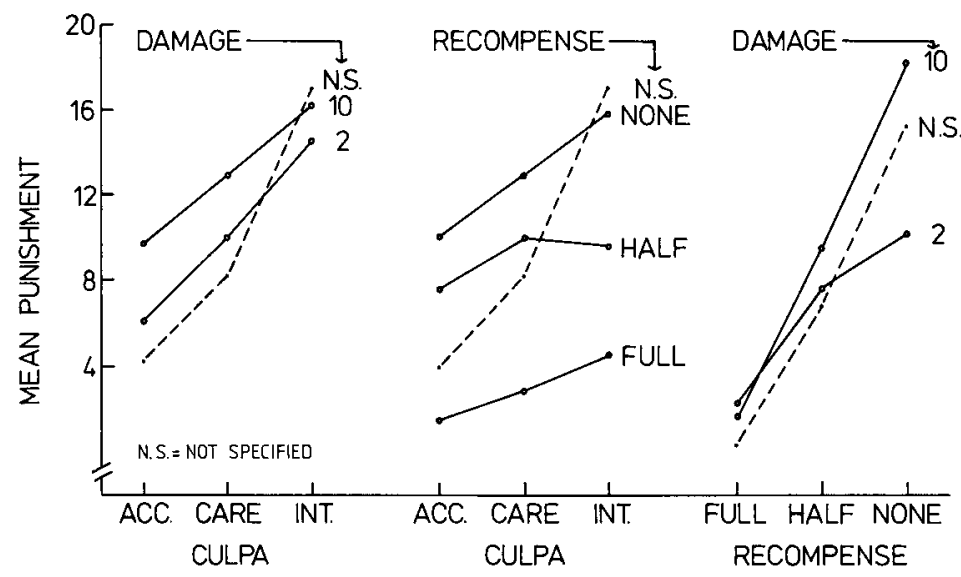

FIGURE 9.1. Assigned punishment as a function of culpa, damage, and recompense. Each panel gives factorial graph for one two-factor design, with the two moral variables listed as curve parameter and on horizontal axis. Dashed curves denote response to single moral variable listed on horizontal axis ( $A C C$., accidental; $C A R E$, careless; $I N T$., intentional)

ments based on just one variable. In the left panel, for example, the label N.S. means that damage was not specified so the judgment was made only on the basis of culpa. The fact that the dashed curve crosses over one or more of the solid curves provides the critical support for averaging.

The logic of this crossover test (Anderson, 1981) applies as follows to the present task. In the left panel, both the additive and the averaging rules can account for the parallelism of the solid curves, but only the averaging rule can account for the crossover. To see this, note that the dashed curve represents judgments based on culpa information alone. Comparison of the dashed curve with the solid curve labeled 2 shows what happens when the information is added that two stamps were damaged. If this information had an additive effect, then the solid curve would have to lie entirely on one side of the dashed curve. This prediction does not require that the additive effects be mathematically exact, only that the direction of effect be the same at each point. The crossover thus is not consistent with any form of summation model.

Under the averaging hypothesis, the added information about two damaged stamps is averaged in with the culpa information. This is the milder level of damage and may be assumed to have a value around the midpoint of the scale. Since this value is greater than the leftmost point on the dashed curve, averaging it in will raise the response; and since this value is lower than the rightmost point on the dashed curve, averaging it in will lower the response. In this way, the averaging model accounts for the crossover in the left panel of Figure 9.1.

In the other two panels of Figure 9.1, the theoretical issue is to test between the averaging and the multiplying rules. Here again the issue rests on a com- 
parison of the dashed and solid curves. The averaging rule provides a straightforward account of the crossover, in accord with the logic already discussed.

In contrast, the multiplying rule cannot account for these data patterns. This rule requires that the dashed and solid curves form a linear fan with a common point of intersection. But in the center panel, the dashed curve intersects the two solid curves at different elevations, and the solid curves would only intersect if extrapolated to the left. Similarly, in the right panel, the dashed curve intersects the lower solid curve around half recompense, whereas the two solid curves intersect around full recompense. These data pattern are therefore sharply inconsistent with the multiplying rule. In short, these empirical analyses support a revised scheme $\mathrm{S}$ and infirm scheme $\mathrm{M}$.

\section{Paradoxical Effect of Recompense}

Recompense had a much larger effect than the damage for which recompense was given. This, may be seen in Figure 9.1 by comparing the left and center panels. The effect of damage is given by the vertical separation between the two damage curves labeled 2 and 10 in the left panel. Similarly, the effect of recompense is given by the vertical separation among the curves in the center panel. As can be seen, the effect of recompense is three or four times larger than the effect of damage. This is paradoxical because the objective value of recompense is necessarily restricted by the damage.

This paradoxically large effect of recompense has been observed previously (Hommers \& Anderson, 1985, in preparation). The theoretical interpretation is that recompense has two components. One component refers to the actual damage, and constitutes material restitution. The second component refers to the moral character of the harmdoer; recompense decreases the culpa of the harmdoer and thereby decreases the assigned punishment according to the foregoing blame schema. This second component makes it possible for the effect of recompense to be greater than the actual damage.

This large effect of recompense may seem to differ from legal thought. Von Linstow's (1974) formula represented recompense as a multiplicative factor between 0.8 and 1.0. Since this multiplies (culpa+damage), the reduction in punishment could mathematically exceed the damage term, but only if culpa were much larger than damage. But scheme $\mathrm{M}$ cannot account for the threeto-fourfold effect observed in Figure 9.1. On the other hand, the report of Thomas (1970, p. 197) on the sentencing policy of the British Court of Appeal Criminal Division indicates that small amounts of recompense are ineffective: only "quite obviously quite substantial restitution" is an important factor. Although the present experiment did not test small amounts of recompense, the foregoing two-component interpretation implies that even apology or remorse, without any material restitution, could have sizeable effects in contrast to the British Court of Appeal. Of course, this contrast between legal 
thought and everyday morality may reflect the severity of the offenses. Whereas the culpa component may be large relative to a few ruined stamps among friends, it may be small relative to the offenses that reach the courts.

\section{Functional Measurement Methodology}

A detailed exposition of functional measurement cannot be given here, but a few comments are needed to indicate how it may be useful for further study of legal schemes. For illustration, consider the hypothesis that culpa and damage are integrated by an adding-type scheme:

\section{Punishment $=$ Culpa + Damage .}

The natural way to test this scheme is to measure punishment, culpa, and damage, and check whether they do indeed add up. But this imposes stringent measurement conditions. If the three variables are measured on rank-order scales, for example, they will surely not add up. In general, they will only add up if the three variables are measured on true psychological scales, in this case on scales with equal intervals and a known zero point.

How to obtain true psychological scales has been controversial in psychology since Fechner's study of psychophysical laws. Only recently has a method been developed with reasonably general capability for such psychological measurement. One part of this method is the parallelism theorem, which was applied to test the hypothesis that the culpa-damage integration obeyed an adding-type rule. By virtue of the parallelism theorem, an observed pattern of parallel data curves implies an adding-type rule of integration. Prior measurement of culpa and damage is not needed to test this integration rule. No more is necessary than that the response of judged punishment be on a scale with equal intervals - but this itself follows from observed parallelism. The parallelism theorem is thus a powerful tool because it can simultaneously validate the response measure and the integration rule.

The information about the values of the stimulus variables, in this case culpa and damage, is contained in the distances among the points in the graphs. For example, the closeness of the two solid curves in the left panel of Figure 9.1 implies that ten damaged stamps is not considered much worse than two damaged stamps. Recompense had far larger effects, as already noted in the discussion of the vertical separation of the solid curves in the middle panel. These considerations may be put into quantitative form to obtain true psychological scales of the stimulus variables.

Of special importance is that the parallelism theorem can be applied to the data of individual subjects. The graph in the left panel of Figure 9.1 is an average over the group of subjects. Thus, it rests on the uniformity assumption that all subjects are similar with respect to the scheme. But similar graphs can be constructed for each individual using several trials per stimulus to control for 
measurement error. The basic aspect of this topic is taken up later in the discussion of personal design.

Functional measurement methodology is not a routine recipe. Success depends on the use of certain experimental techniques (see Anderson, 1982, Chap. 1). Success also depends heavily on the actual operativeness of algebraic schemes of integration. Fortunately, experimental studies in many different areas of psychology have found extensive evidence for a general cognitive algebra (see Anderson, 1981, Chap. 1). The present experiment may illustrate something of the potential of this approach to test the cognitive validity of schemes of legal thought.

\section{Legal Schemes as Heuristics for Cognitive Science}

The foregoing experimental results have illustrated how legal thought can serve as a heuristic for cognitive science. This approach goes beyond mere comparison of prescriptive schemes with moral cognition to use those schemes as part of substantive inquiry. Two or three aspects of this approach deserve comment.

\section{Structure of Recompense}

The functional measurement analysis yielded an unexpected empirical answer to the two conflicting legal schemes for recompense: Both were partly correct, as represented in the averaging rule. The scale-free tests ruled out the hypothesis of scheme $S$ that recompense operates by simple subtraction. These tests also ruled out the hypothesis of scheme $\mathrm{M}$ that recompense operates by simple multiplication. Instead, the operative rule was found to be averaging with differential weighting. The integration process itself is thus one of subtraction. At the same time, however, the differential weights act multiplicatively as a level-specific modifier on the values of recompense. This differentially weighted averaging produces the fan pattern seen in the middle and right panels of Figure 9.1. At the surface level this fan pattern would seem to support the prescriptive multiplying rule of Von Linstow (1974). The deeper cognitive analysis revealed a rather different and more complex structure of recompense.

The problem of structure also appears in the paradoxical effect of recompense. Although nominally bounded by the actual damage, recompense actually had far larger effects. This result, together with the averaging rule, suggests that recompense may not be a distinct moral category. Thus, the simple prescriptive theory of recompense, where recompense is a mitigating factor only in the case of a "quite obviously quite substantial restitution" (Thomas, 1970 , p. 197), is not valid in layperson's judgments in two respects. First, even half recompense reduced punishment considerably. Second, recompense had 
a more complex structure than culpa and damage, as shown by the differential weighting of recompense instead of constant weighting for culpa and damage. These comments suggest that recompense effects may be mediated by more basic moral categories. Legal thought, as indicated by $\S 46$ of the German Penal code (1975), suggests a two-component structure of recompense (Bruns, 1974, 1980; Maurach, Gössel, \& Zipf, 1978; Zipf, 1977). The act component refers to the actual decrease of damage, and the harmdoer component refers to moral virtue demonstrated by the act itself.

Two directions of further work deserve consideration: (a) the structure of recompense, and (b) the generality and universality of the findings on harm and recompense. With respect to the structure of recompense, further empirical work is needed to explore the two-component theory from $\S 46$ more carefully. For example, the nonadditivity of recompense may be associated with one of the two components inherent in voluntary recompense by the harmdoer: remorse and compensation. This might be studied with a duplex response procedure in which subjects make two separate judgments, one for punishment and one for recompense. These two judgments correspond to the foregoing act and harmdoer components, reflecting the dual structure of civil and criminal law.

With respect to generality, experimental tests are needed with other scenarios than the damaged stamps, which may differ in content, in severeness of the harm, and in complexity of the circumstances. With respect to universality, the validity for different populations, especially for experts such as lawyers and judges, may be examined. Finally, further work may meaningfully extend the general strategy by using other legal schemes as heuristic tools for cognitive science (Hommers, 1981, 1988; Hommers \& Anderson, in preparation).

\section{Process and Value}

The prescriptive schemes of legal thought included a distinction between process and value. Processes should obey general rules, whereas values may be personal. Valuation, of course, is a matter of expert judgment, and is also sensitive to particulars of the actual situation. In legal thought, however, values are not totally personal; much valuation is constrained by the sentencing frames of the Penal codes or by the guidelines ("Taxes") of Court Benches. Nevertheless, the law leaves some room for personal valuation that is not explicitly prescribed and not regarded as error or deviance.

A parallel distinction between general processes and personal values appears in the theory of information integration. Integration theory allows and indeed insists that values are sensitive to individual and situation. The rules for integrating these values, however, are considered to have substantial invariance. This rule generality provides a theoretical foundation for value analysis by means of functional measurement methodology. 
Value analysis, of course, has a different emphasis in legal thought than in the theory of information integration. Integration theory is descriptive and makes no attempt to constrain values to any prescriptive norm. Rather it aims at cognitive analysis, beginning with the problem of measuring personal values. Legal thought, in contrast, tries to standardize and reduce personal values in order to make the sentences of judges more uniform. Despite this prescriptive emphasis, there is a need for cognitive analysis of value in legal judgments. This may be seen in divided court decisions, which presumably result because different judges put different values and weights on the same evidence. Some allowance for personal values is inherent in the operation of legal systems, represented in the discretion of individual judges. Some cases, moreover, are so complicated that experts as well as laypersons may use simplified schemes to integrate the evidence in place of the prescriptive scheme. To determine this, however, requires analysis in terms of personal values. Hence it is desirable, even necessary, to analyze legal judgment within a cognitive framework. This problem is taken up in the following section.

\section{Analysis of Algebraic Schemes in Legal Psychology}

\section{Linear Models for Correlational Analysis}

In legal psychology the statistical approach of linear regression models for correlations is widely used as illustrated in the seminal field studies of bail setting and sentencing reported by Konečni and Ebbesen (1982). This statistical approach depends on aggregating many cases, each coded in terms of pertinent variables. Criminal sentences, for example, could be coded in terms of severity of sentence, together with such predictor variables as kind and severity of offense, extenuating circumstances, prior offenses, and so forth. Thus coded, the data could be subjected to ordinary multiple regression analysis or to log-linear analysis (e.g., Haberman, 1978), which performs similar functions for qualitative, categorical data.

Such statistical analysis has many uses. Foremost is that it provides an overview of the operation of legal systems that is essential for evaluating how and how well they function. Unexpected benefits may also be obtained. For example, a nuisance finding that complicated the statistical analysis of bail setting by Ebbesen and Konečni (1975) was that one or another important piece of information was absent in about $35 \%$ of the cases. This missing information reflects the exigencies and distractions of the courtroom situation. As noted by Anderson $(1976,1981)$, much might be done for justice by the simple device of instituting a standard information schedule for each case.

Nevertheless, this correlational approach has well-known limitations, especially as concerns causal interpretation from the correlational data base. In their study of sentencing, for example, Konečni and Ebbesen (1982) were 
unable to distinguish two simple and quite different causal models. Another example comes from the present experiment, in which the scale-free tests were able to distinguish between the multiplying model and the differential weighted averaging model. The linear regression approach generally cannot distinguish between these two models, although they represent quite different cognitive processes. For cognitive theory, therefore, the statistical approach has limited relevance. The valuation and integration operations in the statistical model are unlikely to bear any clear or definite relation to the valuation and integration processes of individual judges.

As regards valuation, the statistical approach depends on selection and coding of variables, which must then be applied uniformly across a heterogeneous mass of cases. The judge, in contrast, evaluates the evidence by reference to a background of expert knowledge, involving legal, sociological, cultural, and moral variables that have no representation in the statistical model.

As regards integration, the statistical models have repeatedly been shown to misrepresent cognitive process. This has been found in clinical psychology, personnel selection, and Bayesian decision theory, where statistical methods outperformed clinical psychologists in predicting outcome of therapy, but were insensitive and misleading about cognitive process (see Anderson, 1981, pp. 22-23, 91; Wright, 1984, Chap. 6). Some signs indicate the same for legal judgment (Anderson, 1982, pp. 304, 306; Konečni \& Ebbesen, 1975). Moreover, Ebbesen and Konečni (1982, p. $291 \mathrm{ff}$.) found that severity ratings of judges and probation officers contributed most to the sentencing variance. However, no attempt was made to explain the processes that determine the severity ratings. Thus, for analysis of cognitive process, it seems essential to use stronger methods than linear regression.

\section{Observational Analysis}

A natural approach for the study of algebraic schemes in cognitive processes in legal thought and practice is through analysis of actual cases. This may be done phenomenologically, with a focus on single cases, following the case tradition of Anglo-Saxon law. Indeed, judges' opinions constitute a phenomenological data base, for they reflect judges' valuation and integration processes. This is the natural place to begin the study of judicial judgment. Such phenomenological reports can provide priceless information about cognitive processes. Of special interest are background knowledge and cognitive operators developed through extended legal experience.

Judges' opinions are self-report data, of course, and so must be expected to suffer the same limitations and pitfalls that have been found with self-report data throughout psychology. An example appears in Bauer's (1984) study of sentencing by German judges in traffic cases. Although length of sentence had a high correlation with the facts of the case, the written justifications were largely stereotypic commonplaces that had little relation to length of sentence. 
For both legal analysis and cognitive analysis, therefore, in-depth interviews of the judges would be desirable to reduce ambiguity and incompleteness of the written record. In the present approach, however, these phenomenological data are not ends in themselves, but rather a beginning for experimental analysis. The problem is to find some way to embed experimental analysis of cognitive process within realistic legal settings. This problem is considered next.

\section{Embedding Method and Personal Design}

A primary goal of the present theory is to unite phenomenological and experimental analysis for the study of judgment and decision in natural settings. Phenomenological analysis can provide invaluable clues about cognition, but these clues are notoriously fallible. In the meaning constancy studies of person cognition, for example, it seemed phenomenological clear and apparent that trait adjectives strongly affected each others' meanings in a person description. Cognitive analysis showed this to be untrue (Anderson, 1981, Chap. 3). The methods of information integration theory were able to distinguish cognitive reality from phenomenologically illusion. This unified phenomenological-experimental approach may be obtainable with use of embedding method and personal design.

The embedding method, as the name suggests, involves embedding an integration task within a relevant social context. The purpose of the embedding is to allow experimental manipulation of some stimulus information within the chosen social context. Personal design carries this to the limit by constructing the integration task within the knowledge system of a selected individual.

Embedding within a legal setting could begin with a base case from some actual jurisdiction, selected to allow realistic manipulation of relevant variables. Multiple variants would then be constructed, each differing in realistic specifics from the base case. Such variables could include purposiveness of the offense, extenuating circumstances, motivation and personal character of the harmdoer, and so forth. By using factorial-type design, as in the present experiment, the patterning in the data can allow straightforward diagnosis of certain integration rules, as illustrated in Figure 9.1. Although group data were analyzed here, the same procedures can be applied to individual data.

Personal design carries the embedding method further by using the individual for selection both of the base case and of the stimulus information variables. Since task and design are both personalized, the assumption of uniformity across subjects would no longer be necessary. Moreover, phenomenological and prior observational analyses could be incorporated within a rigorous experimental design and extended through experimental analysis. Personal design can allow for knowledge that does not ascend to the level of consciousness and phenomenological report. Many cognitive factors will never reach the phenomenological level. These include unconscious or unverbalizable motivations, as well as cultural and judicial assumptions so taken for granted that the judge is unaware of making them. This application 
of the functional measurement methodology may provide a validational framework for phenomenology and observation in case studies that enables separation of cognitive reality from phenomenological illusion.

Some loss of realism is inevitable even with the embedding method. A personal design would ordinarily be presented in the quiet of a judge's chambers, not in the hubbub of the courtroom. Missing, therefore, would be multifarious aspects of courtroom atmosphere, including informational cues not in the personal design, together with lapses of attention and flashes of humor and irritation that distinguish an actual court. But what is being studied is the cognitive system of the judge, which is assumed to be the same in chambers as on the bench. The integration rules may thus be expected to have reasonable generality, even though the specific information being integrated may differ markedly across cases. The valuation processes, similarly, may be expected to be reasonably general, even though the specific information being evaluated is variable across cases. Although loss of courtroom realism could be serious for sociological studies of actual outcomes, many process questions can be studied outside of the actual courtroom.

Personal design would be expected to elucidate the judge's ideal of justice, which may differ from courtroom practice for various reasons already indicated. If this is a limitation, it is also an advantage, and it may even be instructive for judges to face their actual mode of operation dissected in this manner (Anderson, 1976).

The case method of instruction in law has an important similarity to the embedding method. Study of past cases in lawbooks may actually have less realism than cases in a personal design, yet it is a preferred mode of instruction. The case method could, moreover, be coupled with the embedding method. Law students would thus consider not just the single case, but a number of variant cases designed to have legal interest and to satisfy conditions for functional measurement. In this way, it would be possible to embed the study of legal cognition within legal curricula.

Acknowledgment. This work was supported by a grant from the Stiftung Volkswagenwerk, Hannover, Federal Republic of Germany, by Grant Ho 920/2-1 from the Deutsche Forschungsgemeinschaft, and by Grant BNS82-12461 from the National Science Foundation.

\section{References}

Anderson, N. H. (1976). Social perception and cognition (Tech. Rep. CHIP 62). San Diego: La Jolla: Center for Human Information Processing, University of California.

Anderson, N. H. (1981). Foundations of information integration theory. New York: Academic.

Anderson, N.H. (1982). Methods of information integration theory. New York: Academic. Anderson, N.H. (1983). Psychodynamics of everyday life: blaming and avoiding blame (Tech. Rep. CHIP 120). San Diego: La Jolla: Center for Human Information Processing. University of California. 
Bauer, G. (1984). Der Strafzumessungsvorgang als stufenweise Konkretisierung des gesetzlichen Strafrahmens. Mannheim: Jur. Diss.

Berscheid, E., \& Walster, E. (1967). When does a harmdoer compensate a victim? Journal of Personality and Social Psychology, 6, 435-441.

Bruns, H. J. (1974). Strafzumessungsrecht. Gesamtdarstellung (2nd. ed.). Cologne: Heymanns.

Bruns, H. J. (1980). Leitfaden des Strafzumessungsrechts. Cologne: Heymanns.

Ebbesen, E. B., \& Konečni, V. J. (1975). Decision making and information integration in the courts. The setting of bail. Journal of Personality and Social Psychology, 32, 805-821.

Haberman, S. J. (1978). Analysis of qualitative data: Vol. 1. New York: Academic.

Hommers, W. (1981). Recht und Psychologie: ein wechselseitiges Verhältnis. In W. Michaelis (Ed.), Bericht über den 32. Kongreß der Deutschen Gesellschaft für Psychologie in Zürich 1980 (pp. 699-704). Göttingen: Hogrefe.

Hommers, W. (1983a). Zur quantitativen Theorie von Wiedergutmachungskognitionen unter Gewinnung ihrer Grundmerkmale aus der Jurisprudenz. In G. Lüer (Ed.), Bericht über den 33. Kongreß der Deutschen Gesellschaft für Psychologie in Mainz 1982 (pp. 588-595). Göttingen: Hogrefe.

Hommers, W. (1983b). Die Entwicklungspsychologie der Delikts- und Geschäftsfähigkeit. Göttingen: Hogrefe.

Hommers, W. (1985). Recht und Psychologie: ein wechselseitiges Verhältnis - zur Gegenstandsbestimmung der Rechtspsychologie. Universitas, 39, 1323-1332.

Hommers, W. (1986). Ist „Voller Ersatz“ immer „Adäquater Ersatz?“ Zu einer Diskrepanz zwischen Regelungen des Gesetzbuches im EXODUS und der Adäquatheits-These der Equity-Theorie. Psychologische Beiträge, 28, 164-179.

Hommers, W. (1988). Implizite Willenstheorien des rechtlichen Denkens aus empirischpsychologischer Perspektive. In H. Heckhausen, F. Weinert, \& F. E. Gollwitzer (Eds.), Wollen und Handeln. Berlin Heidelberg New York: Springer.

Hommers, W. (in press). Implicit phsychological theories of legal thought on sentence and liability. In P. J. Van Koppen, \& D. J. Hessing (Eds.), Lawyers on psychology and psychologists on law. Amsterdam: Swets \& Zeitlinger.

Hommers, W., \& Anderson, N.H. (1985). Recompense as a factor in assigned punishment. British Journal of Developmental Psychology, 3, 75-86.

Hommers, W., \& Anderson, N. H. (in preparation). Moral algebra of harm and recompense.

Konečni, V.J., \& Ebbesen, E. B. (Eds.). (1982). The criminal justice system: a socialpsychological analysis. San Francisco: Freeman.

Leon, M. (1980). Integration of intent and consequence information in children's moral judgments. In F. Wilkening, J. Becker, \& R. Trabasso (Eds.), Information integration by children. Hillsdale, NJ: Erlbaum.

Maurach, R., Gössel, K. H., \& Zipf, H. (1978). Strafrecht. Allgemeiner Teil: Part 2 (5th ed.). Heidelberg: Müller.

Piaget, J. (1932). The moral judgment of the child. London: Kegan Paul.

Surber, C.F. (1982). Separable effects of motives, consequences, and presentation order on children's moral judgments. Developmental Psychology, 18, 257-266.

Thomas, D. A. (1970). Principles of sentencing. The sentencing policy of the court of appeal criminal division. London: Heinemann.

Von Linstow, B. (1974). Berechenbares Strafmaß. Berlin: Schweitzer.

Wright, G. (1984). Behavioral decision theory. Beverly Hills, CA: Sage.

Zipf, H. (1977). Die Strafzumessung. München: Beck. 